\title{
Efficacy of Three Different Alpha 1-Adrenergic Blockers and Hyoscine N-Butylbromide for Distal Ureteral Stones
}

\author{
M. Cenk Gurbuz, Haci Polat, Lutfi Canat, Mert Kilic, Turhan Caskurlu \\ Istanbul Goztepe Training Hospital, Department of 2nd Urology, Istanbul, Turkey
}

\begin{abstract}
Purpose: To evaluate hyoscine N-butyl bromide (HBB) and three different alpha-1 blockers in the treatment of distal ureteral stones.

Materials and Methods: A total of 140 patients with stones located in the distal tract of the ureter with stone diameters of 5 to $10 \mathrm{~mm}$ were enrolled in the present study and were randomized into 4 equal groups. Group 1 received HBB, Group 2 received alfuzosin, Group 3 received doxazosin and Group 4 received terazosin. The subjects were prescribed diclofenac injection $(75 \mathrm{mg}$ ) intramuscularly on demand for pain relief and were followed-up after two weeks with x-rays of the kidneys, ureters, bladder and urinary ultrasonography every week. The number of pain episodes, analgesic dosage and the number of days of spontaneous passage of the calculi through the ureter were also recorded.

Results: The average stone size for groups 1, 2, 3 and 4 was comparable $(6.13,5.83,5.59$ and $5.48 \mathrm{~mm}$ respectively). Stone expulsion was observed in $11 \%, 52.9 \%, 62 \%$, and $46 \%$ in groups $1,2,3$ and 4 respectively. The average time to expulsion was $10.55 \pm 6.21$ days in group $1,7.38 \pm 5.55$ days in group 2, $7.85 \pm 5.11$ days in group 3 and $7.45 \pm 5.32$ days in group 4. Alpha blockers were found to be superior to $\operatorname{HBB}(\mathrm{p}<0.05)$.

Conclusions: Medical treatment of distal ureteral calculi with alfuzosin, doxazosin and terazosin resulted in a significantly increased stone-expulsion rate and decreased expulsion time when compared with HBB. HBB seems to have a negative effect on stone-expulsion rate.
\end{abstract}

Key words: ureteral calculi; medical expulsive therapy; adrenergic alpha-antagonists; hyoscine N-butyl bromide Int Braz, J Urol. 2011; 37: 195-202

\section{INTRODUCTION}

Recently, medical expulsion therapy (MET) has been investigated as a supplement to observation in an effort to improve spontaneous stone passage rates. Several agents have been studied as potential METs. Glyceryltrinitrate, calcium channel antagonists, corticosteroids, parasympatholytic agents and alpha-blockers have all been evaluated as therapies to promote ureteral stone expulsion, with inconsistent results (1-3). Alpha-blockers are a particularly promising class of stone-expulsive agents (4). The proposed mechanism of their action is the selective relaxation of ureteral smooth muscle, which results in the inhibition of ureteral spasms and the dilatation of the ureteral lumen, especially the distal part of the ureter.

Anti-spasmodic agents, such as hyoscine -Nbutylbromide, are often prescribed by general practitioners or by emergency services as soon as renal colic is diagnosed. HBB may help provide analgesia by inducing smooth muscle relaxation, which decreases 
ureteral spasm. For this reason, anti-spasmodic agents are still recommended in the treatment of renal colic, usually as adjuvant therapy to NSAIDS and/or opioids (5).

Tamsulosin has been the most commonly studied alpha-1 blocker in the treatment of ureteral stones with increased spontaneous stone expulsion; however, the efficacy of other alpha-blockers has not been well studied, although many are less costly and more available than tamsulosin. Studies that have assessed anti-spasmodic agents primarily focused on the effect of pain management in renal colic treatment. For this reason, a prospective randomized study was planned to compare the effectiveness of three different types of non-specific alfa1-adrenoreceptor antagonists and HBB for relieving ureteral colic and facilitating the spontaneous expulsion of distal ureteral stones.

\section{MATERIALS AND METHODS}

A total of 140 adult patients who were admitted to the Urology Clinic with complaints of renal colic were prospectively evaluated between August 2008 and April 2009. The study was approved by the local Ethics Committee. Patients who had radioopaque stones located in the distal tract of the ureter with stone diameters of 5 to $10 \mathrm{~mm}$ were included in the study.

Exclusion criteria were as follows: presence of urinary tract infection, diabetes mellitus, pregnancy, renal insufficiency (serum creatinine greater than $1.8 \mathrm{mg} / \mathrm{dL}$ ), a solitary kidney, radiolucent stones, multiple stones, a previous history of distal ureter surgery, severe hydronephrosis, current alpha-blocker use or allergic reaction to the study medication.

All patients were evaluated with $\mathrm{x}$-rays of the kidneys, ureters, and bladder as well as ultrasonography of the urinary system. Stone size was recorded for each patient. The treatment was fully explained to patients before obtaining informed consent.

Patients were randomly divided into four groups. Each group initially included 35 patients. Group 1 received HBB (30 mg oral tablet three times a day); Group 2 received alfuzosin (10 mg daily); Group 3 received doxazosin (4mg daily) and Group 4 received terazosin (5 mg daily). Alpha-blocker drugs were administered before going to bed in the evening. The patients receiving terazosin and doxazosin were started on their therapeutic doses upon entering the study rather than being titrated to that dose. All patients were instructed to drink at least $3 \mathrm{~L}$ of fluids daily. The patients were prescribed a diclofenac injection $(75 \mathrm{mg})$ intramuscularly on demand for pain relief. The subjects were advised to filter their urine, and those who had passed their stones were asked to stop taking the medication. The patients were followed-up weekly for up to two weeks with x-rays of the kidney, ureter and bladder region, and urinary ultrasonography and urine analysis were performed to exclude infection.

Subjects recorded daily pain using a visual analog pain score (linear 11-point scale from 0 , no discomfort, to 10 , the most severe pain ever experienced), and they maintained a pain medicine diary that recorded the number of doses of diclofenac medication consumed per day. The date and time of stone passage were recorded. The criteria for treatment discontinuation and the need for hospitalization and/or endoscopic treatment were intolerable pain, fever and/or the development of new severe hydronephrosis or worsening of already present hydronephrosis, or lack of success of stone expulsion after two weeks.

Two endpoints were chosen to determine the effect of alpha-blockers and HBB on the treatment of ureter stones, stone expulsion rate and pain score reduction.

Statistical analyses were performed with ANOVA and Pearson's chi-square test using the parameters of stone size, expulsion rate, time to expulsion, amount of analgesic compound and number of pain episodes. A value of $\mathrm{P}<0.05$ was statistically significant.

\section{RESULTS}

There were no statistically significant differences between the groups with respect to age, sex, stone size, baseline degree of hydronephrosis present and previous stone passage history (Table-1). Stone expulsion was observed in 3 of 33 patients in group $1(11 \%), 18$ of 34 patients in group $2(52.9 \%), 20$ of 
Table 1 - Patients characteristics.

\begin{tabular}{|c|c|c|c|c|c|c|}
\hline & & HBB & Alfuzosin & Doxazosin & Terazosin & p Value \\
\hline Mean age & & $40.3 \pm 15.9$ & $40.31 \pm 11.4$ & $34.17 \pm 1.1$ & $38.17 \pm 11.3$ & 0.283 \\
\hline Male-Female (\%) & & $68 \%-22 \%$ & $59 \%-41 \%$ & $41 \%-59 \%$ & $65 \%-35 \%$ & 0.065 \\
\hline Stone size $(\mathrm{mm})$ & & $7.13 \pm 1.11$ & $6.83 \pm 1.76$ & $6.59 \pm 1$ & $6.48 \pm 1.72$ & 0.626 \\
\hline $\mathrm{HN}$ & $\begin{array}{l}0 \\
1 \\
2\end{array}$ & $\begin{array}{r}74 \% \\
8 \% \\
18 \%\end{array}$ & $\begin{array}{l}48 \% \\
35 \% \\
17 \%\end{array}$ & $\begin{array}{l}51 \% \\
34 \% \\
15 \%\end{array}$ & $\begin{array}{l}45 \% \\
31 \% \\
24 \%\end{array}$ & 0.477 \\
\hline Previous stone passage & $\begin{array}{l}\text { Yes } \\
\text { No }\end{array}$ & $\begin{array}{l}34 \% \\
66 \%\end{array}$ & $\begin{array}{l}26 \% \\
74 \%\end{array}$ & $\begin{array}{l}18 \% \\
72 \%\end{array}$ & $\begin{array}{l}35 \% \\
65 \%\end{array}$ & 0.715 \\
\hline
\end{tabular}

$H N=$ hydronephrosis; $G 1=$ grade $1 ; G 2=$ grade $2 ; H B B=$ hyoscine $N$-butyl bromide .

32 patients in group $3(62 \%)$, and 14 of 31 patients in group $4(45.16 \%)$. In groups 2,3 and 4 , the rate of the spontaneous passage of the calculi was found to be higher compared with that in group $1(\mathrm{P}<0.05)$ (Table-2). There was no difference detected between the alpha-blocker groups with respect to the rate of the spontaneous passage of the stones.

Average time to expulsion was $10.55 \pm 6.21$ days in group $1,7.38 \pm 5.55$ days in group $2,7.85 \pm$ 5.11 days in group 3 and $7.45 \pm 5.32$ days in group 4. Time to expulsion was recorded significantly less often in groups 2, 3 and 4 than in group $1(\mathrm{P}<0.05)$. However, no significant difference was noted between groups 2,3 and $4(\mathrm{p}=0.756)$. Decreases in baseline pain were noted in 53\%, 55.6\%, 51\% and 52\% with the use of HBB, alfuzosin, doxazosin and terazosin, respectively (Figure-1). When comparing the improvement in the baseline pain score, there were no significant differences between the groups $(p=0.567)$. Similarly, the mean number of diclofenac administrations was observed to be similar in the groups ( $\mathrm{p}=$ 0.567) (Table-2).

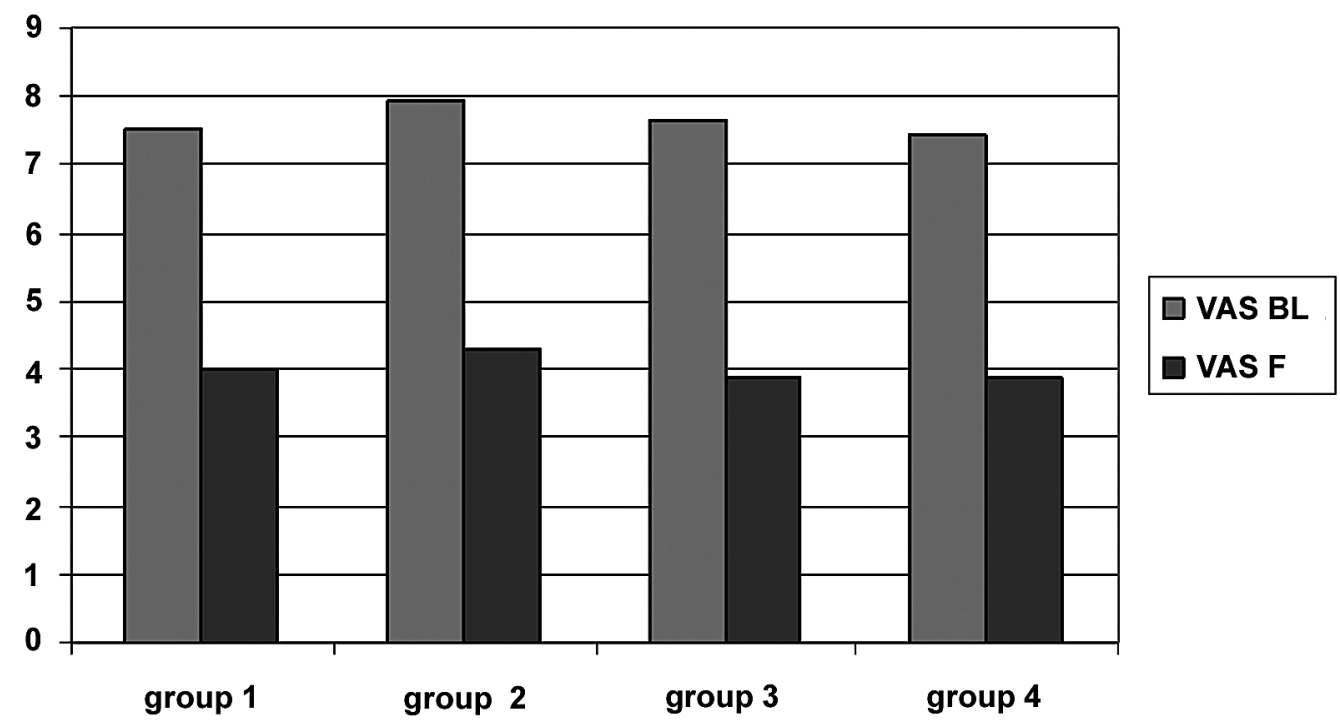

Figure 1 - Visual analogue scale scores at baseline and follow-up in the groups. 
Table 2 - Follow-up results of the group.

\begin{tabular}{|c|c|c|c|c|c|c|}
\hline & & HBB & Alfuzosin & Doxazosin & Terazosin & p Value \\
\hline Stone expulsion rate $(\%)$ & & 11 & 52.9 & 62 & 45.16 & 0.05 \\
\hline Mean day to expulsions & & $10.55 \pm 6.21$ & $7.38 \pm 5.55$ & $7.85 \pm 5.11$ & $7.45 \pm 5.32$ & 0.05 \\
\hline \multirow{2}{*}{ Decrease pain score (VAS) } & $\mathrm{BL}$ & $7.50 \pm 2.4$ & $7.94 \pm 2.1$ & $7.64 \pm 2.8$ & $7.44 \pm 2.3$ & \multirow{2}{*}{0.567} \\
\hline & $\mathrm{F}$ & $3.98 \pm 2.5$ & $4.3 \pm 2.4$ & $3.9 \pm 2.3$ & $3.9 \pm 2.6$ & \\
\hline Diclofenac requirement (n) & & $3.75 \pm 1.9$ & $4.36 \pm 2.3$ & $4.36 \pm 2.4$ & $4.46 \pm 1.3$ & 0.667 \\
\hline
\end{tabular}

$B L=$ baseline $;=$ follow-up $; H B B=$ hyoscine $N$-butyl bromide $;$ VAS = visual analog scale.

Of the 140 patients, 10 were removed from the study due to urinary tract infection, patient request for intervention and lack of compliance in 5,2 and 3 patients, respectively. Requiring to stop the medication due to the adverse events was not recorded in the groups.

\section{COMMENTS}

The availability of minimally invasive treatment alternatives and the high success of extracorporeal shockwave lithotripsy (ESWL), emergency ESWL and ureteroscopic extractions have greatly changed the way in which stone treatment is approached (6). However, urologists are often doubtful about the best form of therapy and should consider the possibility of spontaneous passage of stones or the use of medical therapy. With the introduction of MET, the clinical treatment of ureteral stones has undergone a major evolution. Treatment regimens involving alpha adrenergic drugs are aimed at promoting ureteral smooth muscle relaxation. Alpha-1-adrenergic receptor antagonists have some degree of selectivity for the detrusor muscles and distal ureter and have thus been investigated for their potential to promote stone expulsion and decrease pain $(7,8)$. Because there is no need to titrate the dose, tamsulosin has been the most commonly studied alpha-blocker in the treatment of ureteral stones (9-11). Alpha-blockers are still an off-label treatment for ureteral stones. We aimed to evaluate the effectiveness of the other three alpha-blockers, which are less expensive and more available than tamsulosin. Ureteral stones are most prevalent in patients between the ages of 40 and 45 (12), and with respect to cardiovascular stability, this population is relatively more stable than patients diagnosed with benign prostatic hyperplasia (BPH). Dose titration with doxazosin and terazosin, which is recommended in the management of $\mathrm{BPH}$, may not be required for this particular population. In this study, patients receiving terazosin and doxazosin were started on their therapeutic doses upon inclusion into the study rather than being titrated to that dose.

HBB acts by inhibiting cholinergic transmission in the abdominal-pelvic parasympathetic ganglia, thus relieving spasm in the smooth muscles of the gastrointestinal, biliary, and urinary tract (13). In Turkey HBB is the most prescribed agent for the symptomatic treatment of renal colic. To our knowledge, the present study is the first to compare the effectiveness of HBB and nonselective alpha-1 blockers in the treatment of ureteral stones.

In complete obstruction, the signs of kidney injury appear within three to four weeks (14). For this reason, clinicians may wait up to four weeks to see if the stones will pass spontaneously, provided that the patient is comfortable. Studies with MET showed that $80-90 \%$ of stone expulsion occurs within 15 days (15). In the current study, intervention was suggested after a two week follow-up. It was determined that the stone expulsion rate for three different alpha-adrenergic blockers was significantly higher when compared to the HBB group (alfuzosin, $52.9 \%$; doxazosin, $62 \%$; terazosin, 45.16\%; HBB, 11\%). In addition, alphablockers were better than HBB with respect to the time to the spontaneous passage of the stones (7.5 days versus 10.55 days). The pain medicine require- 
ment also decreased significantly with alpha-blockers; however, this difference was not significant when compared with HBB.

Yilmaz et al. compared the efficacy of three different alpha-adrenergic blockers (16). The stone expulsion rates of tamsulosin, terazosin, and doxazosin were found to be $79.31 \%, 78.57 \%$, and $75.86 \%$, respectively. The mean time to passage was significantly lower in the groups receiving alpha-1 blockers compared with the control group. In the present study, the stone-expulsion rates were found to be $62 \%$ and $45.1 \%$ in the doxazosin and terazosin group, respectively. A meta-analysis of 11 clinical trials that enrolled a total of more than 900 patients suggested that alpha-blockers increase the rate of spontaneous stone passage by $44 \%$ (17). Tamsulosin has been the most commonly studied alpha-1 blocker in the treatment of ureteral stones. Direct comparison of alfuzosin and tamsulosin in the management of lower ureteral calculi has shown that both drugs increase the stone-expulsion rate $(82.3 \%$ vs. $70.5 \%)$, decrease expulsion time (12.3 versus 14.5) and reduce the need for analgesics (18). Ukhal et al. found that the rate for the spontaneous passage of distal ureteral stones with doxazosin was $71.1 \%$ and demonstrated that the drug decreases the frequency of renal colic (19).

In the present study, the expulsion-rate of stones using alpha-blockers was slightly lower than the literature findings. Our explanations are as follows: 1) Steroids or anti-edema agents have generally been included in medical treatment for their anti-inflammatory action, presumably to reduce local edema; however, in our study, no steroids were used. 2) A factor that might have affected stone-expulsion rate other than stone size might have been the duration of colic and the degree of impaction and obstruction by the stone, which was not addressed in the current study. 3) Stone sizes $<5 \mathrm{~mm}$ were also included in previous reports. 4) The duration of MET was longer in previous reports. In our study, stone sizes $<5 \mathrm{~mm}$ were excluded, and the duration of MET was two weeks.

Anti-spasmodic agents such as HBB may theoretically help provide analgesia by inducing smooth muscle relaxation, which decreases ureteral spasm. For this reason, anti-spasmodic agents are still recommended in the treatment of renal colic, but with inconsistent clinical benefit (20). Most studies administering anti-spasmodic agents focused only on the control of analgesic symptoms for renal colic due to ureteral stone. The current study was performed to assess and compare the expulsive effects of orally administered HBB and alpha-blockers. Dabella et al. evaluated the expulsive effects of orally administered phloroglucinol, tamsulosin and nifedipine for distal ureteral stone (3). The expulsion rate was found to be higher for tamsulosin, followed by nifedipine and phloroglucinol; the expulsion rates were $97.1 \%$ and $77.1 \%$, $64.3 \%$, respectively. Surprisingly, the expulsion rate in the HBB group was found to be $11 \%$ in the current study. The relatively larger stone size and the lack of corticosteroid administration may explain the lower expulsion rate. Pain relief of $53 \%$ was noted on the visual analog scale with the use of HBB, which was similar to that of the alpha-blockers. The efficacy of HBB can only be due to a reduction in ureteral hypermotility, as no direct analgesic property of the compound has been documented at the dose used. We speculate that the lower stone-expulsion rate in HBB may be due to its anti-spasmodic effect, resulting in the diminished ureteral activity necessary for stone expulsion.

With regard to the two end points of the current trial, all three alpha-blockers proved to be superior to HBB. Treatment to relieve the pain associated with ureteral colic was found to be similar for all groups.

\section{CONCLUSIONS}

Alpha-1 blockers, regardless of the type, were found to be effective in the treatment of distal ureteral stone in terms of stone expulsion and pain control. HBB was found to be effective at controlling pain; however, the effect of stone expulsion was lower than that of alpha-blockers. HBB seems to have a negative effect on stone expulsion. The major limitation of the current study was the small sample size. Further studies may be needed to evaluate the effect of antispasmodic agents and non-tamsulosin alpha-blockers in the treatment of ureteral stones. 


\section{CONFLICT OF INTEREST}

None declared.

\section{REFERENCES}

1. Saita A, Bonaccorsi A, Marchese F, Condorelli SV, Motta M: Our experience with nifedipine and prednisolone as expulsive therapy for ureteral stones. Urol Int. 2004; 72 (Suppl 1): 43-5.

2. Porpiglia F, Ghignone G, Fiori C, Fontana D, Scarpa RM: Nifedipine versus tamsulosin for the management of lower ureteral stones. J Urol. 2004; 172: 568-71.

3. Dellabella M, Milanese G, Muzzonigro G: Randomized trial of the efficacy of tamsulosin, nifedipine and phloroglucinol in medical expulsive therapy for distal ureteral calculi. J Urol. 2005; 174: 167-72.

4. Lipkin M, Shah O: The use of alpha-blockers for the treatment of nephrolithiasis. Rev Urol. 2006; 8(Suppl 4): S35-42.

5. Maclean A, Dunn R: Renal/Urology. In: R Dunn (ed.), The Emergency Medicine Manual. West Beach, Venom Publishing. 2000; pp. 437-9.

6. Ghalayini IF, Al-Ghazo MA, Khader YS: Evaluation of emergency extracorporeal shock wave lithotripsy for obstructing ureteral stones. Int Braz J Urol. 2008; 34: 433-40; discussion 441-2.

7. Weiss RM: Physiology and pharmacology of the renal pelvis and ureter. In: Walsh PC, Retik AB, Vaughan ED Jr, Wein AJ (ed.), Campbell's Urology, Philadelphia, Saunders. 2002; pp. 399-400.

8. Sigala S, Dellabella M, Milanese G, Fornari S, Faccoli S, Palazzolo F, et al.: Evidence for the presence of alpha1 adrenoceptor subtypes in the human ureter. Neurourol Urodyn. 2005; 24: 142-8.

9. De Sio M, Autorino R, Di Lorenzo G, Damiano R, Giordano D, Cosentino L, et al.: Medical expulsive treatment of distal-ureteral stones using tamsulosin: a single-center experience. J Endourol. 2006; 20: 126.

10. Resim S, Ekerbicer H, Ciftci A: Effect of tamsulosin on the number and intensity of ureteral colic in patients with lower ureteral calculus. Int J Urol. 2005; 12: 61520.

11. Gravina GL, Costa AM, Ronchi P, Galatioto GP, Angelucci $\mathrm{A}$, Castellani $\mathrm{D}$, et al.: Tamsulosin treatment increases clinical success rate of single extracorporeal shock wave lithotripsy of renal stones. Urology. 2005; 66: 24-8.
12. Scales CD Jr, Curtis LH, Norris RD, Springhart WP, Sur RL, Schulman KA, et al.: Changing gender prevalence of stone disease. J Urol. 2007; 177: 979-82.

13. Tytgat GN: Hyoscine butylbromide: a review of its use in the treatment of abdominal cramping and pain. Drugs. 2007; 67: 1343-57.

14. Menon M, Parulkar BG, Drach,GW: Urinary lithiasis: etiology, diagnosis and medical management. In: Walsh PC, Retik AB, Vaughan ED, Wein AJ. (ed.), Campbell's Urology, Philadelphia, Saunders. 1998; pp. 2702-18.

15. Porpiglia F, Ghignone G, Fiori C, Fontana D, Scarpa RM: Nifedipine versus tamsulosin for the management of lower ureteral stones. J Urol. 2004; 172: 568-71.

16. Yilmaz E, Batislam E, Basar MM, Tuglu D, Ferhat M, Basar H: The comparison and efficacy of 3 different alpha1-adrenergic blockers for distal ureteral stones. J Urol. 2005; 173: 2010-2.

17. Parsons JK, Hergan LA, Sakamoto K, Lakin C: Efficacy of alpha-blockers for the treatment of ureteral stones. J Urol. 2007; 177: 983-7; discussion 987.

18. Agrawal M, Gupta M, Gupta A, Agrawal A, Sarkari A, Lavania P: Prospective randomized trial comparing efficacy of alfuzosin and tamsulosin in management of lower ureteral stones. Urology. 2009; 73: 706-9.

19. Ukhal' MI, Malomuzh OI, Strashnyi VV, Shumilin MV: The use of the alpha 1-adrenoblocker doxazosin in the pharmacotherapy of disorders of urine outflow of spastic origin. Lik Sprava. 1998; 8: 118-21.

20. Holdgate $\mathrm{A}, \mathrm{Oh} \mathrm{CM}$ : Is there a role for antimuscarinics in renal colic? A randomized controlled trial. J Urol. 2005; 174: 572-5; discussion 575.

Accepted after revision:

July 30, 2010

\section{Correspondence address:}

Dr. M. Cenk Gurbuz

K1sıklı mahallesi, İlkkent Camlık Sitesi

B Blok D 12, Üsküdar

Istanbul, Turkey

Fax: + 90053 2317-3186

E-mail: gurbuzcenk@yahoo.com 


\section{EDITORIAL COMMENT}

Medical expulsive treatment for ureterolithiasis has received considerable attention in the contemporary literature. Ureteral stone are extremely common urological emergencies. It accounts for approximately one million visits to emergency room in the United States alone (1). Interventional treatment particularly minimally invasive options like shock wave lithotripsy and ureteroscopy are commonly performed. Open surgery has now become a story of the past (2).

Recent advances in understanding the dynamics of urine flow through the ureter have greatly helped in the development of drugs for the initial management of symptomatic ureterolithiasis. The colic pain results from an increase in the intra ureteral and intra renal pressure secondary to the inability of ureteral peristalsis to move the urine distal to the obstructing stone. The main factors associated with stone obstruction are ureteral muscle spasm, sub mucosal edema, pain, and infection within the ureter. It seems logical that medical therapy address these factors. Several medications, including steroids, calcium channel blockers, alpha-adrenergic antagonists (3) and non-steroidal anti-inflammatory drugs, have been used to aid in the spontaneous passage of distal ureteral calculi. Recently, use of selective alpha-blockers has shown promise for medical expulsion therapy (MET) of distal ureteral calculi. Contemporary evidence in literature indicates that both selective agents, like naftopidil (4) and non selective agents like doxazosin (3) are equally efficacious. Authors' in the current work have studied the efficacy of hyoscine N-butyl bromide (HBB) and three different alpha-1 blockers in the treatment of distal ureteral stones. They noted that medical treatment of distal ureteral calculi with alfuzosin, doxazosin and terazosin resulted in a significantly increased stone-expulsion rate and decreased expulsion time when compared with HBB. Not surprisingly they also noted that HBB seems to have a negative effect on stone-expulsion rate. HBB is a quaternary ammonium compound which blocks the action of acetylcholine at parasympathetic sites (both muscarinic and nicotinic receptors) in smooth muscle, and in secretory glands. It causes decreased motility of the urogenital tracts, and is useful in the treatment of spasms. The stimulation of alpha 1 -adrenergic receptors increases ureteral peristaltic frequency, smooth muscle tonus and contractile force, resulting in ureteral spasm and decreased ureteral flow. Conversely blockade of these receptors induces the inhibition of basal tone, peristaltic amplitude and frequency, and decreased intra ureteral pressure. Dellabella et al. (5) proposed that alpha 1 -adrenergic receptor antagonists increase the urine bolus and subsequently increase pressure above the stone, while below the stone intraureteral pressure is decreased because of inhibited peristaltic amplitude and frequency. Thus, alpha 1-blockers induce an increase in the intra ureteral pressure gradient around the stone.

The current evidence suggest that MET with alpha-blockers or calcium channel blockers augments stone expulsion rates, reduces the time to stone expulsion, and lowers analgesia requirements for ureteral stones with and without ESWL for stones $<10 \mathrm{~mm}$. There is some evidence that a combination of alpha-blockers and corticosteroids might be more effective than treatment with alphablockers alone. Renal stones after ESWL also seem to profit from MET. The vast majority of randomized studies reported are small, single-centre studies, limiting the grade of recommendation. Therefore, large multicentre, randomized, placebo-controlled trials are needed.

\section{REFERENCES}

1. Brown J: Diagnostic and treatment patterns for renal colic in US emergency departments. Int Urol Nephrol. 2006; 38: 87-92.

2. Ather MH, Paryani J, Memon A, Sulaiman MN: A 10-year experience of managing ureteric calculi: changing trends towards endourological intervention--is there a role for open surgery? BJU Int. 2001; 88: 173-7.

3. Zehri AA, Ather MH, Abbas F, Biyabani SR: Preliminary study of efficacy of doxazosin as a medical expulsive therapy of distal ureteric stones in a randomized clinical trial. Urology. 2010; 75: 1285-8. 
4. Sun X, He L, Ge W, Lv J: Efficacy of selective alpha1D-blocker naftopidil as medical expulsive therapy for distal ureteral stones. J Urol. 2009; 181: 171620.
5. Dellabella M, Milanese G, Muzzonigro G: Efficacy of tamsulosin in the medical management of juxtavesical ureteral stones. J Urol. 2003; 170: 2202-5.

\section{Dr. M. Hammad Ather}

Section of Urology, Department of Surgery Aga Khan University Karachi, Pakistan

E-mail:hammad.ather@aku.edu 